\title{
Acute kidney injury requiring dialysis in obstetric patients: management and clinical outcome in case series of 30 patients in a tertiary care centre
}

\section{Molina U. Patel ${ }^{1 *}$, Yuvraj Jadeja ${ }^{1}$, Niket Patel ${ }^{1}$, Nayana Patel ${ }^{2}$, Smruti Vaishnav ${ }^{1}$, Harsha Bhadarka ${ }^{2}$}

${ }^{1}$ Department of Obstetrics and Gynecology, Shree Krishna Hospital and HM Patel Centre for Medical Education and Research, Karamsad, Gujarat, India

${ }^{2}$ Department of Embryology, Akanksha Hospital and Research Institute, Anand, Gujarat, India

Received: 27 April 2017

Accepted: 22 May 2017

*Correspondence:

Dr. Molina U. Patel,

E-mail: drmolinapatel@gmail.com

Copyright: (c) the author(s), publisher and licensee Medip Academy. This is an open-access article distributed under the terms of the Creative Commons Attribution Non-Commercial License, which permits unrestricted non-commercial use, distribution, and reproduction in any medium, provided the original work is properly cited.

\section{ABSTRACT}

Background: Acute Kidney Injury is a common medical problem affecting approximately 5\% of all hospitalized and $30 \%$ of critically ill patients. The incidence in obstetric patients ranges from 1 in 2000 to 1 in 25000 pregnancies. In India till date, the impact of AKI on fetomaternal outcome and pertaining therapeutic interventions is only sparsely studied.

Methods: It is a retrospective cross-sectional study. All obstetric patients with AKI on dialysis, admitted to Shree Krishna Hospital, a tertiary care hospital in Karamsad village in Gujarat from January 2013 to August 2015. Multivariate statistical analysis of clinical and laboratory parameters was performed using SPSS program to obtain the results.

Results: The incidence of dialysis was $1.6 \%$. HELLP syndrome and pre-eclampsia (80\%) was found to be the most common etiology of AKI followed by Congestive cardiac failure (34.5\%), hemorrhage and sepsis in $30 \%$ resp. All patients were admitted to ICU care. No significant difference was found between SAP II and SOFA monitoring system. Mechanical ventilation was done to support 53.3\% and inotropic support was needed by $56.7 \%$ patients. According to the RIFLE criteria, majority of the patients fall under risk category followed by injury. $18 \%$ of the patients developed End Stage Renal Disease.

Conclusions: In view of the multifaceted etiologies and complexity of management of AKI, a multi-disciplinary approach involving nephrologist, intensivists, obstetricians and neonatologists is extremely important.

Keywords: Dialysis, ICU, RIFLE, SAP II, SOFA

\section{INTRODUCTION}

Acute kidney injury (AKI) is a clinical syndrome denoted by an abrupt decline in glomerular filtration rate (GFR) sufficient to decrease the elimination of nitrogenous waste products (urea and creatinine) and other uremic toxins. ${ }^{1}$ The incidence has decreased in developed countries over the last 60 years from 1 in 3000 in the mid
20 century to 1 in $20,000 .^{2}$ However, AKI still comprises $25 \%$ of referrals to dialysis center in developing countries. ${ }^{3}$ The incidence ranges from $4.3 \%$ to $14.5 \%$ in India. ${ }^{4}$

The maternal mortality associated with AKI has been reported from $9 \%$ to 55\%.5 The Poverty, lack of awareness and timely diagnosis, poor sensitivity towards 
the issue, technical and infrastructural problems like lack of transport or timely availability of obstetric care and blood products are all responsible for this additional burden ${ }^{6}$

A major limitation in improving outcome of AKI has been the absence of common standards for diagnosis and classification.

The RIFLE criteria are an international classification which was published in May 2004 by the Acute Dialysis Quality Initiative (ADQI), for stratifying acute kidney diseases. It is based on the Risk, Injury, Failure, Loss of kidney function and End stage kidney disease. Its implication determines the Length of stay in ICU, renal recovery and overall morbidity and mortality in AKI patients.The significance and application of RIFLE criteria has been evaluated in clinical practice and seem to have a correlation to outcomes in patients with $\mathrm{AKI}^{7}$

Hence, incidence of obstetric and peripartum patients with ICU admissions in developed countries can reach up to $10 \%$ or more in developing countries. ${ }^{8}$

Scoring in intensive care units (ICUs) has been often used for individual patient or group prediction and for evaluating and comparing the performance of different ICUs. ${ }^{9}$

General illness severity scores in the ICU helps to predict outcome, characterize disease severity and degree of organ dysfunction. These scores are complimentary to ICU care. It is shown that Simplified Acute Physiological (SAP) score and Sequential Organ Failure Assessment (SOFA) score could be reliable indicators. Since most of the patients of AKI require intensive care treatment, comparative evaluation of ICU scoring systems like SAP II and SOFA, is of great clinical significance for monitoring of critical mothers.

Amongst the various specific and generic scores, this study aims to calculate and compare SAP II and SOFA scores for ICU monitoring. The SAP II score is an outcome prediction score which takes into consideration variables like Age, temp, SBP, HR, GCS, BUN, K+, Na, $\mathrm{HCO}_{3}$, bilirubin, $\mathrm{PaO}_{2} / \mathrm{Fio}_{2}$, while the SOFA score is an Organ dysfunction score, that takes into consideration six organ systems.

AKI patients develop multi organ failure faster than non AKI patients.

In obsterics, the incidence of dialysis ranges from 1 in 8,000 upto 1 in 20,000 women. The indications of dialysis in obstetric patients are as follows:

- Uremic symptoms (encephalopathy, pericarditis or neuropathy

- Volume overload
- Hyperkalemia and/or metabolic acidosis unresponsive to initial medical treatment.

- When GFR falls to below $20 \mathrm{ml} / \mathrm{min}$ per $1.73 \mathrm{~m}^{2}$

ICU mortality is three times higher in AKI than in other patients. Oliguric AKI was an independent risk factor for overall mortality. Presence of infection or cardiovascular failure further increased the morbidity and mortality. ${ }^{10}$

- To date, the impact of AKI on fetomaternal outcome and pertaining therapeutic interventions is only sparsely studied. This study provides the few crucial steps in better understanding of AKI in the following manner:

- To find out the incidence of obstetric patients requiring haemodialysis in case of Acute kidney injury.

- To study the association and aetiology of Acute kidney injury in obstetric patients undergoing haemodialysis.

- To distribute patients having Acute renal injury according to RIFLE criteria.

- To compare SOFA score and SAPS II score as prognostic indicators of outcome in intensive care unit in obstetric patients with AKI.

\section{METHODS}

This study was retrospective cohort study based on the review of medical records.

\section{Inclusion criteria}

All Obstetric patients who are known case / have developed AKI and require dialytic treatment in the hospital.

\section{Exclusion criteria}

Patients who are already undergoing dialysing treatment since past.

The study group included 30 postpartum and obstetric patients with AKI, requiring dialytic treatment, admitted to Shree Krishna Hospital , a tertiary care hospital in Karamsad village in Gujarat from January 2013 to June 2015.AKI was classified according to the RIFLE criteria.

Retrospective data collection was done with the help of Medical records department and prefomed clinical proforma was filled.

Written and informed consent was taken from HREC and the Medical Records department of Shree Krishna Hospital, Karamsad to help in providing necessary data for the study. The privacy of the data was maintained. The identity and personal information of the patients was kept confidential. 


\section{Statistical analysis}

Descriptive statistics for categorical and continuous variables and for comparing 2 continuous variables, paired $\mathrm{t}$ test is used.

\section{RESULTS}

Out of the 1625 high risk obstetric admissions at SKH in 2 years in present study, the incidence of AKI (according to the RIFLE criteria) was found to be $17.84 \%$. And the incidence of haemodialysis was found to be $1.8 \%$.

Table 1: Demographic profile of patients.

\begin{tabular}{|lll|}
\hline Age group & Frequency & $\%$ \\
\hline$(11-20)$ years & 5 & 16.7 \\
\hline$(21-30)$ years & 17 & 56.7 \\
\hline$(31-40)$ years & 7 & 23.3 \\
\hline$(41-50)$ years & 1 & 3.3 \\
\hline
\end{tabular}

Table 1 shows the demographic profile of the patients.56 $\%$ of the study group were in the age range of 31 to 40 years. The mean age group was found to be 31.7 years.
Table 2: Type of admission.

\begin{tabular}{|lll|}
\hline Type of admission & N & $\%$ \\
\hline Emergency & 3 & 10 \\
\hline Non-emergency referral & 6 & 20 \\
\hline Emergency referral & 21 & 70 \\
\hline
\end{tabular}

Table 2 shows that $70 \%$ of the patients were emergency referrals and $30 \%$ were routine non-emergency referrals. $60 \%$ of the patients had taken antenatal care, majority at primary health care centres and few at private practitioners. The referrals were from hospitals, private practitioner's primary and community health care centres in and around Kheda District, Gujarat.66\% were referred in their antenatal period where as the rest were postpartum referrals. Looking into the socio-economic background of our study group, $80 \%$ belonged to low socioeconomic strata and had received either no or less than primary education.

Table 3 shows the upper, lower and mean values of the lab parameters of the study group. All major parameters are evaluated and overall decreasing trend can be observed.

Table 3: Laboratory parameters.

\begin{tabular}{|ll|lll|}
\hline Parameter & Minimum & Maximum & Mean & STD deviation \\
\hline $\mathrm{Hb}(\mathrm{gm} / \mathrm{dl})$ & 1.5 & 13 & 6.11 & 2.99 \\
\hline Total count $(\mathrm{cells} / \mathrm{cmm})$ & 1600 & 51700 & 22889 & 10629 \\
\hline Platelet (cells/cmm) & 26000 & 670000 & 140800 & 107605 \\
\hline Sodium $(\mathrm{mEq} / \mathrm{L})$ & 124 & 149 & 133 & 5.6 \\
\hline Potassium (mEq/L) & 2.8 & 6.7 & 4.0 & 0.9 \\
\hline Total bilirubin $(\mathrm{mg} / \mathrm{dl})$ & 0.14 & 14.8 & 2.5 & 3.6 \\
\hline Direct bilirubin $(\mathrm{mg} / \mathrm{dl})$ & 0.07 & 12 & 1.7 & 2.9 \\
\hline Indirect bilirubin $(\mathrm{mg} / \mathrm{dl})$ & 0.02 & 3.7 & 0.7 & 0.84 \\
\hline Creatinine $(\mathrm{mg} / \mathrm{dl})$ & 0.70 & 8.11 & 3 & 26.7 \\
\hline BUN $(\mathrm{mg} / \mathrm{dl})$ & 20 & 147 & 45 & 16.7 \\
\hline PT $($ seconds) & 11 & 60 & 28 & 33.6 \\
\hline aPTT (seconds) & 22.1 & 120 & 60 & 1.4 \\
\hline INR & 1.0 & 1 & 5.7 & \\
\hline
\end{tabular}

Table 4 shows the range of presenting clinical signs and symptoms. As expected, majority had decreased urine output $(96.7 \%)$, fever $(86.70 \%)$, Bleeding per vaginum (76.7), altered sensorium (46.70\%), headache (30\%), other symptoms such as irrelevant talking, burning micturition, blurring of vision etc were also seen.

Table 5 shows the associated comorbidities and obstetric complications associated with these patients of AKI, which could be a potential risk factor in the development of AKI. The range of hospital stay was 4 to 63 days with the mean duration of stay being $14 \pm 2$ days.
Table 4: Clinical presentation.

\begin{tabular}{|lll|}
\hline Symptom & Frequency & $\%$ \\
\hline Decreased urine output & 29 & 96.7 \\
\hline Fever & 26 & 86.7 \\
\hline Bleeding per vaginum & 23 & 76.7 \\
\hline Altered sensorium & 14 & 46.7 \\
\hline Leaking per vaginum & 11 & 23.3 \\
\hline Headache & 9 & 30 \\
\hline Blurring of vision & 7 & 24.7 \\
\hline Prelabour pains & 4 & 13.3 \\
\hline
\end{tabular}


Table 5: Associated obstetric comorbidities.

\begin{tabular}{|lll|}
\hline Cause & Frequency & $\%$ \\
\hline Pre-renal & & \\
\hline Congestive cardiac failure & 10 & 34.5 \\
\hline Obstetric haemorrhage & 9 & 31 \\
\hline Sepsis & 9 & 31 \\
\hline Hyperemesis gravidarim & 1 & 3.3 \\
\hline Renal & & \\
\hline Hellp/pre-ecclampsia & 24 & 80 \\
\hline Glomerulonephritis & 1 & 3.3 \\
\hline Post-renal & & \\
\hline Obstruction & 2 & 6.7 \\
\hline Grvaid uterus & 3 & 10 \\
\hline
\end{tabular}

Delay in the initiation of treatment was associated with greater number of hospital days and higher number of haemodialysis cycles.

Table 6: Association of number of dialysis cycles with total number of cycles required.

\begin{tabular}{|lllll|}
$\begin{array}{l}\text { No. } \\
\text { of } \\
\text { cycle }\end{array}$ & $\begin{array}{l}\text { Immediate } \\
\text { Dialysis }\end{array}$ & $\begin{array}{l}\text { Dialysis } \\
\text { within } \\
\mathbf{4 8 ~ h r s}\end{array}$ & $\begin{array}{l}\text { Dialysis } \\
\text { within } \\
\mathbf{4 8 - 7 2} \text { hrs }\end{array}$ & $\begin{array}{l}\text { Dialysis } \\
\text { after } 72 \\
\text { hrs }\end{array}$ \\
\hline 1 & $57.1 \%$ & $57.1 \%$ & - & $14.3 \%$ \\
\hline 2 & $14.3 \%$ & $14.3 \%$ & $50 \%$ & $14.3 \%$ \\
\hline 3 & $28.6 \%$ & $14.3 \%$ & $50 \%$ & $28.6 \%$ \\
\hline 4 & - & $14.3 \%$ & - & - \\
\hline 5 & - & - & - & $42.9 \%$ \\
\hline & $\mathrm{n}=7$ & $\mathrm{n}=14$ & $\mathrm{n}=2$ & $\mathrm{n}=7$ \\
\hline
\end{tabular}

Table 6 shows the association of number of cycles of dialysis required during hospital stay in relation to the initiation of first dialysis. 7 patients underwent immediate dialysis, 14 within 8 hours, 2 patients within $48-72$ hours, 7 after 72 hours.

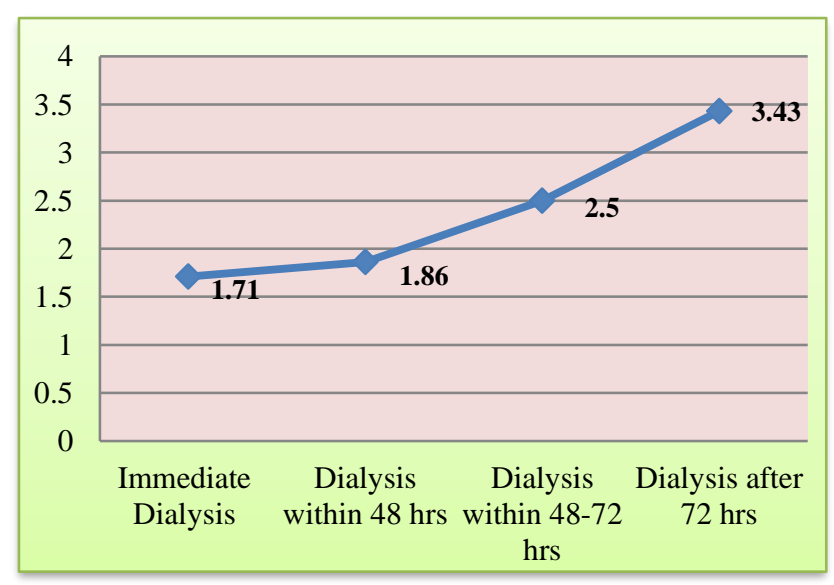

Figure 1: Correlation of mean dialysis cylces with time of initiation.

Figure 1 shows that correlation of the mean number of dialysing cycles with the time interval of initiation of the dialysis.
Table 7: ICU characteristics.

\begin{tabular}{|lll|} 
& $\begin{array}{l}\text { Mechanical } \\
\text { ventilation }\end{array}$ & $\begin{array}{l}\text { Inotropic } \\
\text { support }\end{array}$ \\
\hline Yes & 16 & 17 \\
\hline No & 14 & 13 \\
\hline
\end{tabular}

Table 7 shows that $100 \%$ of the patients required ICU admission and intensive care monitoring. $53.3 \%$ of the patients required mechanical ventilation and $56.7 \%$ needed inotropic support i.e either noradrenaline and dopamine.

Table 8: Blood components required.

\begin{tabular}{|ll|}
\hline Product & N \\
\hline PCV & 30 \\
\hline FFP & 20 \\
\hline CRYO & 8 \\
\hline PLT & 10 \\
\hline
\end{tabular}

Table 8 shows the requirement of blood components in our study. All 30 patients required transfusion of blood components. $100 \%$ of the patients required PCV transfusion, $66 \%$ required fresh frozen plasma, $33 \%$ required platelet concentrates and $30 \%$ required cryoprecipitates.

Table 9: Classification according to RIFLE criteria.

\begin{tabular}{|l|l|} 
Classification & $\begin{array}{l}\text { N } \\
\text { Total high risk obstetric } \\
\text { patients=1625, } \\
\text { Total number of deliveries = 2500 }\end{array}$ \\
\hline Risk & 210 \\
\hline Injury & 50 \\
\hline Failure & 09 \\
\hline Loss & 3 \\
\hline ESRD & 18 \\
\hline
\end{tabular}

The classification of the patients according to the RIFLE criteria can be seen in Table 9 .

Table 10: ICU prediction scores SAP II and SOFA.

\begin{tabular}{|llll|}
$\begin{array}{l}\text { Scoring } \\
\text { model }\end{array}$ & Mean score & Mortality & P value \\
\hline SOFA & $13.66 \pm 4.50$ & $40-50 \%$ & $<0.001$ \\
\hline SAP II & $30.18 \pm 16.27$ & upto $30 \%$ & $<0.001$ \\
\hline
\end{tabular}

Table 10 shows the mean SAP II and SOFA scores and its associated mortality prediction in our study. Both the scores show significant effectiveness when tested in collaboration. However, there was no significant difference in the predictive value for the 2 scores.

Figure 2 represents the comparison of SAP II and SOFA score, which were found to be indentical for patient monitoring. 12 patients took Discharge Against Medical 
Advice (DAMA), 1 took transfer to another hospital on patient demand, 5 patients were discharged on request and 7 were discharged as per doctors advice. 5 patients faced mortality.

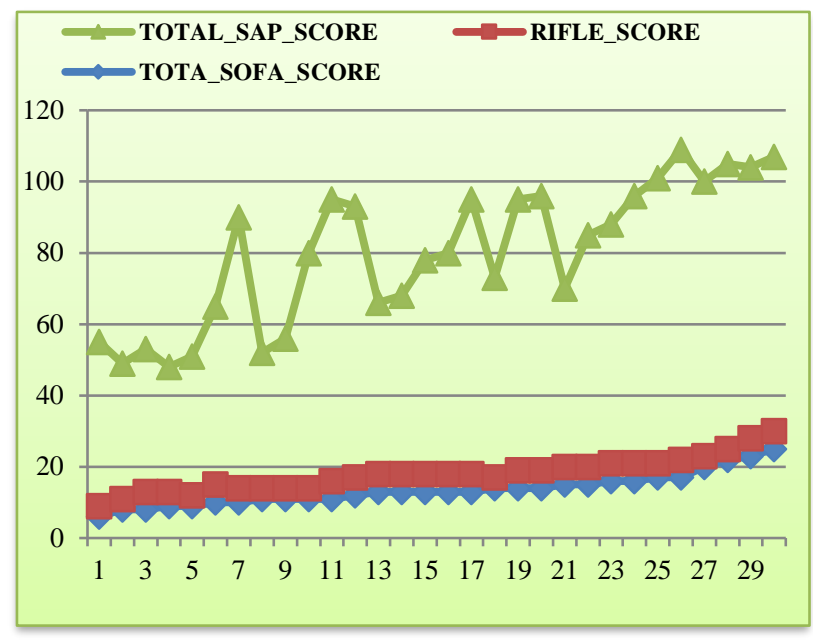

Figure 2: Comparison between SAP II and SOFA scores.

Table 11 depicts the obstetric outcome in our study. Of the 20 antenatal patients, 3 underwent emergency LSCS for obstetric indication, 1 patient had an instrumental vaginal delivery by outlet forceps. Rest were vaginal deliveries out of which, 5 were preterm, 20 were Intra uterine fetal death.

Table 11: Obstetric outcome.

\begin{tabular}{|lll|}
\hline Obstetric outcome & Frequency & $\%$ \\
\hline Intra uterine fetal death (IUFD) & 20 & 66.7 \\
\hline LSCS & 3 & 10.0 \\
\hline Preterm vaginal delivery & 5 & 16.7 \\
\hline Instrumental vaginal delivery & 1 & 3.3 \\
\hline
\end{tabular}

For the fetal outcome, both in patient and outside deliveries were considered. Intra uterine fetal death was the most common outcome ocurring in $66.7 \%$ of the cases. $33.3 \%$ of the babies had ELBW, 30\% were low birth weight, while $6.7 \%$ of the babies weighed $>2.5 \mathrm{Kg}$.

\section{DISCUSSION}

Acute kidney injury (AKI) is classically defined as an abrupt and sustained decrease in renal function. ${ }^{11} \mathrm{AKI}$ cases can be dated back to the 1960's. The incidence has decreased from $1 / 3000$ to $1 / 20,000$ today. Over the past 20-30 years medical complications of pregnancy remained a regular and frightening reason for acute renal referrals. Frightening because patients are young and healthy till days before, with unfamiliar and rapidly changing physiology. At SKH, the incidence of AKI was found to be $17.8 \%$ and that of haemodialysis was $1.84 \%$
There is no consensus on the exact cut offs for the diagnosis of AKI. This challenge not only leads to conflicting reports in literature but is also believed to be a major obstacle to research in this field. ${ }^{12} \mathrm{~A}$ standard way of diagnosing AKI has been introduced with the acute kidney injury network (AKIN), RIFLE, and the kidney disease improving global outcomes (KDIGO) guidelines. ${ }^{13}$ In present study, we have classified the patients according to the RIFLE criteria. The aetiology of obstetrical ARF has also changed over the last few decades. Like in non-pregnant patients, etiology in pregnancy for AKI can be classified under 3 heads, namely pre renal, renal and post renal.

In present study, the main cause of developing AKI having renal cause was found to be HELLP syndrome / pre ecclampsia $(80 \%)$. A similar study conducted in Canada by Mehrabadi A et al also reported that there was increasing incidence of obstetric acute kidney injury attributed to hypertensive disorders of pregnancy as also noticed by Munib S and Khan SJ. ${ }^{14,15}$ Amongst the pre renal etiology, in present study, Congestive cardiac failure $(34.5 \%)$, Sepsis $(31 \%)$ and obstetric heamorrhage $(31 \%)$ were important causes.

In a study performed by Koroshi et al, obstetric hemorrhage alone was responsible for $7-39 \%$ of AKI cases, whereas Patel ML et al $(41.7 \%)$, Kilari SK et al $(39.02 \%)$ and Goplani KR et al $(61.42 \%)$ reported septicemia as the commonest cause. ${ }^{16-18}$ The proportion of ARF secondary to septic abortions has decreased from $33.3 \%$ to $1.8 \%$ over the past 20 years. This may be attributed to timely availability of antibiotics, better infection control practises, legalization of abortion, improved government strategies for safe abortion etc. However, in present study, septicemia was seen to have a larger incidence comparatively. 5 patients had AKI due to post renal etiology namely, obstruction and back pressure due to term gravid uterus.

In present study, $70 \%$ of the cases were referred to emergency from nearby tertiary care hospitals, primary or community health centres around Kheda district, Gujarat, with $93.3 \%$ of the cases being referred within 2 weeks from onset of complaints. This shows the lack of sensitivity and knowledge in the system towards early and timely management for AKI in obstetric patients.

We also found that early initiation of dialysis cycles was associated with requirement of less number of mean cycles and faster recovery. Immediate dialysis was limited to a mean of 1.71 cycles which increased to 3.43 mean cycles for dialysis done after 72 hours. $60 \%$ of the patients that developed AKI were $>30$ years of age, thus confirming the fact that higher age group can be associated with development of renal pathology. In present study $10(66.6 \%)$ were multipara. This finding is consistent with the findings of $76.55 \%$ (Munib $\mathrm{S}$ and Khan SJ) $68.57 \%$ (Goplani KR et al) who also reported multiparity in their patients. ${ }^{19,20}$ 
The most common clinical presentation at the time of ICU admission was decreased urine output (96.7), fever $(86.7 \%)$, bleeding per vaginum $(76.7 \%)$, altered sensorium (46.7\%) and headache $(31 \%)$. However, presentations like irrelevant talking $(30 \%)$, blurring of vision $(24.1 \%)$, etc were also seen.

In present study, $17.2 \%$ of the patients had a very preterm delivery $(<32$ weeks), while $66.7 \%$ delivered preterm ( $<36$ weeks). Preterm delivery can be attributed to the coexisting risk factors like severe $\mathrm{PIH}$, abrupio placenta, severe IUGR etc, where in early delivery was indicated to optimize fetomaternal outcome. $10 \%$ of the patients underwent an emergency LSCS, whereas established preterm labour and PROM led to preterm vaginal delivery in $16.7 \%$ of the cases.

Sudden intra uterine fetal death was found to be the most common obstetric outcome in $66.7 \%$ of the cases.The relation of IUFD with AKI is well known, as most of the IUFD patients were referred, the exact timing of fetal demise cannot be commented upon, thus making it difficult to predict weather AKI was secondary to IUFD or IUFD was due to AKI is not clear. 1 patient delivered by instrumental vaginal delivery (Outlet forceps).

The neonatal outcome of the patients was found to have $33.3 \%$ of the patients being ELBW, and $30 \%$ were VLBW and LBW each respectively. Only $6.7 \%$ of the babies weighed $>2.5 \mathrm{Kg}$. The neonatal mortality rate was found to be $9 \%$ in present study. Thus, stressing the fact that timely diagnosis and delivery of the fetus in a centre with well equiped NICU, goes a long way in improving the outcome of both mother and fetus in patient of AKI.

In the classification, according to the RIFLE criteria, (210) $12.9 \%$ of the patients were at Risk, (50) $3 \%$ had Injury, while (18) $1.1 \%$ of the patients developed ESRD. Amongst the 30 patients in present study, as mentioned in results $12(40 \%)$ took discharge against medical advice (DAMA) for financial constraints. 1 patient was transferred to other hospital on patient demand.

5 patients took discharge on request and 7 patients were discharged after recovery, hence, 12 patients had good outcome. All these 12 patients came for regular follow up and were ultimately weaned of dialysis within 6 months, their creatinine levels also normalised, which tells us that timely and appropriate management of these patients leads to good outcome and decrease long term co morbidity. 5 mortality cases were recorded. These patients had developed ESRD, which made their survival poor.

Amongst the 5 patients, who were non-survivors, the major RIFLE category was found to be Loss (50\%) and ESRD (50\%). Oliguria was majorly correlated with mortality in current study, followed by sepsis, need for mechanical ventilation and the use of vasoactive drugs followed by coagulation disorders and anaemia. The mortlity rate in this study was found to be $16.6 \%$ with reference to other studies, Kilari SK et al reported $24.39 \%$ mortality, Goplani KR et al (18.57\%), Patel ML et al $(15 \%)$ and Munib S (12.5\%). All 30 patients required ICU admission. In present study, we have calculated SAP II and SOFA score for each patients and compared them. The SAP II and SOFA score were comparable for ICU monitoring and were not significantly distinct from each other for outcome prediction.

\section{CONCLUSION}

AKI in obstetric patients represents a small group of high risk but significant. A multifaceted approach along with highly expert team consisting of physician, intensivists, obstetrician, anaesthesiologist, neonatologist and nephrologist is required for effective care.

\section{Funding: No funding sources}

Conflict of interest: None declared

Ethical approval: The study was approved by the Institutional Ethics Committee

\section{REFERENCES}

1. Jefferson A, Thurman JM, Schrier RW. Pathophysiology and etiology of acute kidney injury. In: Floege J, Johnson RJ, Feehally J. Comprehensive Clinical Nephrology;2007:806-7.

2. Stratta P, Besso L, Canavese C, Grill A, Todros T, Benedetto C, Hollo S, Segoloni GP. Is pregnancyrelated acute renal failure a disappearing clinical entity? Ren Fail. 1996;18:575-84.

3. Selcuk NY, Onbul HZ, San A, Oda-bas AR. Changes in frequency and etiology of acute renal failure in pregnancy.1980-1987;20:513-7.

4. Rahman S, Gupta RD, Islam N, Das A, Shaha AK, Khan MA, Rahman MM. Pregnancy related acute renal failure in a tertiary care hospital in Bangladesh. J Med. 2012;13(2):129.

5. RL Mehta, JA Kellum, SV Shah, BA Molitoris, C Ronco, DG Warnock et al. Acute Kidney Injury Network: report of an initiative to improve outcomes in acute kidney injury. Crit Care. 2007;11(2):1-8.

6. Ansari MR, Laghari MS, Solangi KB. Acute renal failure in pregnancy: one year observational study at Liaquat University Hospital, Hyderabad. J Pak Med Assoc. 2008;58(2):61-64.

7. Uchino S, Bellomo R, Goldsmith D, Bates S, Ronco C. An assessment of the RIFLE criteria for acute renal failure in hospitalized patients. Crit Care Med. 2006;34(7):1913-7.

8. Gatt S. Pregnancy, delivery and the intensive care unit: need, outcome and management. Curr Opin. Anaesthesiol. 2003;16:263-7.

9. Le Gall JR. The use of severity scores in the intensive care unit. Intensive Care Med. 2003;31:1618-23. 
10. Gilbert TT, Smulian JC, Martin AA, Ananth CV, Scorza W, Scardella AT et al. Obstetric admissions to the intensive care unit: Outcome and severity of illness. Obstet Gynecol. 2003;102:897-903.

11. KDIGO. Clinical Practice guideline for acute kidney injury. Kidney Int Suppl. 2012;2:8-12.

12. Mehta RL, Kellum JA, Shah SV, Molitoris BA, Ronco C, Warnock DG et al. Acute Kidney Injury Network: report of an initiative to improve outcomes in acute kidney injury. Crit Care. 2007;11(2):1-8.

13. Lopes JA, Jorge S. The RIFLE and AKIN classifications for acute kidney injury: a critical and comprehensive review. Clin Kidney J. 2013;6(1):814.

14. Mehrabadi A, Liu S, Bartholomew S, Hutcheon JA, Magee LA, Kramer MS et al. Hypertensive disorders of pregnancy and the recent increase in obstetric acute renal failure in Canada: population based retrospective cohort study. BMJ. 2014;4731:1-12.

15. Munib S, Khan SJ. Outcomes of pregnancy related acute renal failure. RMJ. 2008;33(2):189-92.

16. Patel ML, Sachan R, Radheshyam PS. Acute renal failure in pregnancy: tertiary centre experience from north Indian population. Niger Med J. 2013;54(3):191-5.
17. Kilari SK, Chinta RK, Vishnubhotla SK. Pregnancy related acute renal failure. J Obstet Gynecol India. 2006;56(4):308-10.

18. Goplani KR, Shah PR, Gera DN, Gumber M, Dabhi M, Feroz A et al. Pregnancy - related acute renal failure: A single center experience. Indian J Nephrol. 2008;18(1):17-21.

19. Munib S, Khan SJ. Outcomes of pregnancy related acute renal failure. RMJ. 2008;33(2):189-92.

20. Haddadi A, Lademani M, Gainier M, Hubert H, Tange J, Micheaux PLD. Comparing the APACHE II, SOFA, LOD, and SAPS II scores in patients who have developed a nosocomial infection. Bangladesh Crit Care J. 2014;2(1):4-9.

Cite this article as: Patel MU, Jadeja Y, Patel N, Patel N, Vaishnav S, Bhadarka H. Acute kidney injury requiring dialysis in obstetric patients: management and clinical outcome in case series of 30 patients in a tertiary care centre. Int J Reprod Contracept Obstet Gynecol 2017;6:2997-3003. 